\title{
Kinetic Modeling of Methanol Synthesis from Renewable Resources
}

\author{
C. Seidel ${ }^{1, *}$, A. Jörke ${ }^{1}$, B. Vollbrecht ${ }^{3}$, A. Seidel-Morgenstern ${ }^{1,2}$, A. \\ Kienle $^{1,2}$ \\ 1 Otto-von-Guericke-Universität, \\ Universitätsplatz 2, D-39106 Magdeburg, Germany \\ 2 Max-Planck-Institut für Dynamik komplexer technischer Systeme \\ Sandtorstrasse 1, D-39106 Magdeburg, Germany \\ 3 Siemens AG Engineering $\&$ Consulting \\ Industriepark Höchst B598, D-65926 Frankfurt am Main, Germany
}

\begin{abstract}
In the present paper new detailed kinetic model for the methanol synthesis from $\mathrm{H}_{2}, \mathrm{CO}_{2}$ and/or $\mathrm{CO}$ using a $\mathrm{Cu} / \mathrm{ZnO} / \mathrm{Al}_{2} \mathrm{O}_{3}$ catalyst is proposed. In contrast to most established models different active surface species for $\mathrm{CO}$ and $\mathrm{CO}_{2}$ hydrogenation are taken into account. It is shown that changes in the relative amounts of these different surface species, which are related to changes in catalyst morphology, play an important role for the dynamic transient behavior. The model is therefore suitable for evaluating new applications in chemical energy storage, where strongly varying ratios of $\mathrm{CO}$ and $\mathrm{CO}_{2}$ are of relevance. The model parameters were fitted to steady state and dynamic experimental data for varying $\mathrm{CO} / \mathrm{CO}_{2}$ feed ratios using global optimization. Identifiability is studied using the Profile-Likelihood method giving rise to a reduced kinetic model.
\end{abstract}

Keywords: methanol synthesis, renewable resources, reaction kinetics, parameter identification

2017 MSC: 00-01, 99-00

\footnotetext{
${ }^{1}$ Author to whom all correspondence should be addressed. Email: carsten.seidel@ovgu.de
} 


\section{Introduction}

Methanol is an important basic chemical in the chemical industry (Fiedler et al. 2000). It can be used as starting material for paraffins, olefins or various organic chemicals like acetic anhydride and as fuel (Asinger, 1986). It is produced con-

5 tinuously in large amounts from synthesis gas using $\mathrm{Cu} / \mathrm{ZnO} / \mathrm{Al}_{2} \mathrm{O}_{3}$ catalysts. The reaction network comprises three main reactions, i.e. hydrogenation of $\mathrm{CO}$ and $\mathrm{CO}_{2}$ as well as the water-gas shift reaction according to

$$
\begin{array}{r}
\mathrm{CO}+2 \mathrm{H}_{2} \rightleftharpoons \mathrm{CH}_{3} \mathrm{OH} \\
\mathrm{CO}_{2}+3 \mathrm{H}_{2} \rightleftharpoons \mathrm{CH}_{3} \mathrm{OH}+\mathrm{H}_{2} \mathrm{O} \\
\mathrm{CO}_{2}+\mathrm{H}_{2} \rightleftharpoons \mathrm{CO}+\mathrm{H}_{2} \mathrm{O} .
\end{array}
$$

口 A very popular and widely known kinetic model was proposed by Graaf et al. (1986, 1988) in the 1980s assuming hydrogenation of CO as dominant path to synthesize methanol. But it is nowadays well accepted that under the reaction conditions employed in the chemical industry direct hydrogenation of CO is negligible (Bussche and Froment, 1996, Chinchen et al. 1987, 1990). ¿Corresponding Langmuir-Hinshelwood kinetics were proposed by Bussche and Froment (1996) and further evaluated in a more recent review by Peter et al. (2012).

With the upcoming "energy revolution", methanol becomes, besides its relevance as C-1 industrial raw material, also an important energy carrier (Olah, 2004). Excess electrical wind or solar energy can be converted to hydrogen and react with $\mathrm{CO}$ and $\mathrm{CO}_{2}$ to methanol for chemical energy storage. Typical sources for $\mathrm{CO}$ and $\mathrm{CO}_{2}$ are biomass and waste streams with variable compositions (Larsen and Sønderberg Petersen, 2013; Martín, 2016, Raeuchle et al. 2016 Olah, 2005). In the case of an energy deficit (e.g. no sun, no wind), methanol can be converted back to electrical energy. This will result in a more flexible use of electrical energy from renewable resources, especially in microgrids. But in this case the methanol reactor may also face strongly varying 
ratios of $\mathrm{CO}$ to $\mathrm{CO}_{2}$ in the feed resulting in more transient modes of operation, where established kinetics are insufficient. Changing requirements on the quality of kinetic models due to these new situations were recently summarized in Kalz et al. (2017). In particular, the fraction of active centers for CO and

30 $\mathrm{CO}_{2}$ hydrogenation and the related catalyst morphology change under transient conditions. Dynamic experiments by Muhler et al. (1994); Peter et al. (2012) showed interesting transient behavior, that was caused by a reversible conversion of the different active centers at the catalyst surface, according to Choi et al. (2001a b); Nakamura et al. (2003). Hence, a catalyst can become more active while facing a certain gas composition, which makes this aspect interesting for non stationary cases and is not taken into account by established kinetics. For this reason the main objective of this paper is to develop an extended reaction kinetic model, that is able to handle transient operating modes and a wide range of feed gas compositions. The paper is based on a comprehensive set of steady brecht (2007) and starts with a detailed Langmuir-Hinshelwood model based on elementary reaction steps as proposed in the same thesis. The model is extended with a dynamic morphology model taking a variable amount of different active centers for each reaction into account. Parameters are fitted to steady

45 state and dynamic experiments for varying ratios of $\mathrm{CO}$ to $\mathrm{CO}_{2}$ using global optimization. Identifiability is critically discussed using the profile likelihood method leading to a simplified kinetic model, which fits the experimental data almost equally well and has improved structural identifiability.

\section{Kinetics of Methanol Synthesis}

so In the remainder, this paper focuses on methanol synthesis from $\mathrm{H}_{2}, \mathrm{CO}$, and $\mathrm{CO}_{2}$ over industrial $\mathrm{Cu} / \mathrm{ZnO} / \mathrm{Al}_{2} \mathrm{O}_{3}$ catalysts with pressure between 50 bar to 100 bar and temperatures between $473.15 \mathrm{~K}$ to $573.15 \mathrm{~K}$ according to Eqs. (1)(3). In this work the following model assumptions are made: The catalyst deactivation is neglected and no side reactions beyond Eqs. (1)-(3) are considered. 
55 The Modeling is based on the Langmuir-Hinshelwood mechanism and consists of three main steps: first adsorption at the surface, reaction at the surface and desorption from the surface. Therefore, an important part of this mechanism is the availability of free active surface centers for the reaction. In the classical approach of Graaf et al. (1986, 1988) or Bussche and Froment (1996), a

6o single type of active centers on the surface is assumed. In contrast to this, more recent studies have shown that different active centers are involved in the methanol synthesis (Choi et al., 2001a; Park et al., 2014a b). In the remainder the following surface centers are considered:

i : $\odot$ for oxidized surface centers, also assumed as active center for CO65 hydrogenation,

ii : * for reduced surface centers, also assumed as active center for $\mathrm{CO}_{2}$ hydrogenation, iii : $\otimes$ as active surface centers for heterolytic decomposition of hydrogen.

The corresponding relative amounts of free surface centers will be denoted below by $\Theta^{\odot}$ for oxidized centers, $\Theta^{*}$ for reduced centers, and $\Theta^{\otimes}$ for hydrogen. Occupation of the center with component ' $\mathrm{i}$ ' is indicated by the corresponding index. In a first step, constant total numbers of oxidized, reduced as well as hydrogen centers are assumed.

\subsection{Detailed Langmuir-Hinshelwood Kinetic Model}

75 As a starting point the kinetic model suggested by Vollbrecht (2007) is considered. This model assumes a constant relative amount of centers for each species. The fraction of free surface centers changes with gas composition and their activity depends on the oxidation state of the catalyst surface. The kinetics is based on the elementary steps listed in tables 1. 3. Therein, rate determining

so steps are labeled as RDS. The other steps are assumed to be much faster such that equilibrium can be assumed for them. 
Table 1: Elementary reaction steps for CO-hydrogenation on a $\mathrm{Cu} / \mathrm{ZnO} / \mathrm{Al}_{2} \mathrm{O}_{3}$ catalyst (Vollbrecht 2007)

\begin{tabular}{ll}
\hline Elementary step & quasi-equilibrium/velocity \\
\hline $\mathrm{CO}+\odot \rightleftharpoons \mathrm{CO} \odot$ & $\Theta_{\mathrm{CO}}^{\odot}=K_{\mathrm{CO}} p_{\mathrm{CO}} \Theta^{\odot}$ \\
$\mathrm{H}_{2}+2 \otimes \rightleftharpoons 2 \mathrm{H} \otimes$ & $\Theta_{\mathrm{H}}^{\otimes}=K_{\mathrm{H}_{2}}^{1 / 2} p_{\mathrm{H}_{2}}^{1 / 2} \Theta^{\otimes}$ \\
$3 \mathrm{H} \otimes+\mathrm{CO} \odot \rightleftharpoons \mathrm{H}_{3} \mathrm{CO} \odot+3 \otimes$ & $\Theta_{\mathrm{H}_{3} \mathrm{CO}}^{\odot}=K_{\mathrm{A} 3} \Theta_{\mathrm{H}}^{\odot} \Theta_{\mathrm{CO}}^{\odot} \Theta^{\otimes}$ \\
$\mathrm{H} \otimes+\mathrm{H} \mathrm{CO} \odot \rightleftharpoons \mathrm{CH}_{3} \mathrm{OH} \odot+\otimes$ & $r_{\mathrm{A} 4}=k_{\mathrm{A} 4}^{+} \Theta_{\mathrm{H}}^{\otimes} \Theta_{\mathrm{H}_{3} \mathrm{CO}}^{\odot}-k_{\mathrm{A} 4}^{-} \Theta_{\mathrm{CH} \mathrm{H}_{3} \mathrm{OH}}^{\odot} \Theta^{\otimes}$ (RDS) \\
$\mathrm{CH} \mathrm{H}_{3} \mathrm{OH} \odot \rightleftharpoons \mathrm{CH}_{3} \mathrm{OH}+\odot$ & $\Theta_{\mathrm{CH}_{3} \mathrm{OH}}^{\odot}=K_{\mathrm{CH}_{3} \mathrm{OH}}^{\odot} p_{\mathrm{CH}_{3} \mathrm{OH}} \Theta^{\odot}$ \\
\hline
\end{tabular}

Table 2: Elementary reaction steps for $\mathrm{CO}_{2}$-hydrogenation on a $\mathrm{Cu} / \mathrm{ZnO} / \mathrm{Al}_{2} \mathrm{O}_{3}$ catalyst (Vollbrecht 2007)

\begin{tabular}{|c|c|}
\hline Elementary step & quasi-equilibrium/velocity \\
\hline $\mathrm{CO}_{2}+\mathrm{O} *+* \rightleftharpoons \mathrm{CO}_{3} * *$ & $\Theta_{\mathrm{CO}_{3}} * *=K_{\mathrm{B} 1} p_{\mathrm{CO}_{2}} \Theta_{\mathrm{O}}^{*} \Theta^{*}$ \\
\hline $\mathrm{H} \otimes+\mathrm{CO}_{3} * *+* \rightleftharpoons \mathrm{HCOO} * *+\otimes+\mathrm{O} *$ & $\Theta_{\mathrm{HCOO}}^{* *}=K_{\mathrm{B} 2} \Theta_{\mathrm{H}}^{\otimes} \Theta_{\mathrm{CO}_{3}}^{*} \Theta_{\mathrm{O}}^{*^{-1}} \Theta^{*} \Theta^{\otimes^{-1}}$ \\
\hline $\mathrm{H} \otimes+\mathrm{HCOO} * * \rightleftharpoons \mathrm{H}_{2} \mathrm{COO} * *+\otimes$ & $r_{\mathrm{B} 3}=k_{\mathrm{B} 3}^{+} \Theta_{\mathrm{H}}^{\otimes} \Theta_{\mathrm{HCOO}}^{* *}-k_{\mathrm{B} 3}^{-} \Theta_{\mathrm{H}_{2} \mathrm{COO}}^{* *} \Theta^{\otimes}(\mathbf{R D S})$ \\
\hline $\mathrm{H} \otimes+\mathrm{H}_{2} \mathrm{COO} * * \rightleftharpoons \mathrm{H}_{3} \mathrm{CO} *+\otimes+\mathrm{O} *$ & $\Theta_{\mathrm{H}_{2} \mathrm{COO}}^{* *}=K_{\mathrm{B} 4}^{-1} \Theta_{\mathrm{H}_{3} \mathrm{CO}}^{*} \Theta_{\mathrm{O}}^{*} \Theta^{\otimes} \Theta_{\mathrm{H}}^{\otimes^{-1}}$ \\
\hline $\mathrm{H} \otimes+\mathrm{H}_{3} \mathrm{CO} * \rightleftharpoons \mathrm{CH}_{3} \mathrm{OH} *+\otimes$ & $\Theta_{\mathrm{H}_{3} \mathrm{CO}}=K_{\mathrm{B} 5}^{-1} \Theta_{\mathrm{CH}_{3} \mathrm{OH}}^{*} \Theta^{\otimes} \Theta_{\mathrm{H}}^{\otimes^{-1}}$ \\
\hline $\mathrm{CH}_{3} \mathrm{OH} * \rightleftharpoons \mathrm{CH}_{3} \mathrm{OH}+*$ & $\Theta_{\mathrm{CH}_{3} \mathrm{OH}}^{*}=K_{\mathrm{CH}_{3} \mathrm{OH}}^{*} p_{\mathrm{CH}_{3} \mathrm{OH}} \Theta^{*}$ \\
\hline $\mathrm{H}_{2}+2 \otimes \rightleftharpoons 2 \mathrm{H} \otimes$ & $\Theta_{\mathrm{H}}^{\otimes}=K_{\mathrm{H}_{2}}^{1 / 2} p_{\mathrm{H}_{2}}^{1 / 2} \Theta^{\otimes}$ \\
\hline $\mathrm{H} \otimes+\mathrm{O} * \rightleftharpoons \mathrm{OH} *+\otimes$ & $\Theta_{\mathrm{O}}^{*}=K_{\mathrm{B} 8}^{-1} \Theta_{\mathrm{OH}}^{*} \Theta^{\otimes} \Theta_{\mathrm{H}}^{\otimes^{-1}}$ \\
\hline $\mathrm{H} \otimes+\mathrm{OH} * \rightleftharpoons \mathrm{H}_{2} \mathrm{O} *+\otimes$ & $\Theta_{\mathrm{OH}}^{*}=K_{\mathrm{B} 9}^{-1} \Theta_{\mathrm{H}_{2} \mathrm{O}}^{*} \Theta^{\otimes} \Theta_{\mathrm{H}}^{\otimes^{-1}}$ \\
\hline $\mathrm{H}_{2} \mathrm{O} * \rightleftharpoons \mathrm{H}_{2} \mathrm{O}+*$ & $\Theta_{\mathrm{H}_{2} \mathrm{O}}^{*}=K_{\mathrm{H}_{2} \mathrm{O}} p_{\mathrm{H}_{2} \mathrm{O}} \Theta^{*}$ \\
\hline
\end{tabular}


Table 3: Elementary reaction steps for reverse-watergas-shift reaction on a $\mathrm{Cu} / \mathrm{ZnO} / \mathrm{Al}_{2} \mathrm{O}_{3}$ catalyst (Vollbrecht, 2007)

\begin{tabular}{llll} 
Elementary step & & \multicolumn{2}{c}{ quasi-equilibrium/velocity } \\
\hline $\mathrm{CO}_{2}+\odot$ & $\rightleftharpoons \mathrm{CO}_{2} \odot$ & $\Theta_{\mathrm{CO}}^{\odot}$ & $=K_{\mathrm{CO}_{2}} p_{\mathrm{CO}_{2}} \Theta^{\odot}$ \\
$\mathrm{CO}_{2} \odot+*$ & $\rightleftharpoons \mathrm{CO} \odot+\mathrm{O} *$ & $r_{\mathrm{C} 2}$ & $=k_{\mathrm{C} 2}^{+} \Theta_{\mathrm{CO}_{2}}^{\odot} \Theta^{*}-k_{\mathrm{C} 2}^{-} \Theta_{\mathrm{CO}}^{\odot} \Theta_{\mathrm{O}}^{*}$ (RDS) \\
$\mathrm{CO} \odot$ & $\rightleftharpoons \mathrm{CO}+\odot$ & $\Theta_{\mathrm{CO}}^{\odot}$ & $=K_{\mathrm{CO}} p_{\mathrm{CO}} \Theta^{\odot}$ \\
$\mathrm{H}_{2}+2 \otimes$ & $\rightleftharpoons 2 \mathrm{H} \otimes$ & $\Theta_{H}^{\otimes}$ & $=K_{\mathrm{H}_{2}}^{1 / 2} p_{\mathrm{H}_{2}}^{1 / 2} \Theta^{\otimes}$ \\
$\mathrm{H} \otimes+\mathrm{O} *$ & $\rightleftharpoons \mathrm{OH} *+\otimes$ & $\Theta_{\mathrm{O}}^{*}$ & $=K_{\mathrm{B} 8}^{-1} \Theta_{\mathrm{OH}}^{*} \Theta^{\otimes} \Theta_{\mathrm{H}}^{\otimes^{-1}}$ \\
$\mathrm{H} \otimes+\mathrm{OH} *$ & $\rightleftharpoons \mathrm{H}_{2} \mathrm{O} *+\otimes$ & $\Theta_{\mathrm{OH}}^{*}$ & $=K_{\mathrm{B} 9}^{-1} \Theta_{\mathrm{H}_{2} \mathrm{O}}^{*} \Theta^{\otimes} \Theta_{\mathrm{H}}^{\otimes}$ \\
$\mathrm{H}_{2} \mathrm{O} *$ & $\rightleftharpoons \mathrm{H}_{2} \mathrm{O}+*$ & $\Theta_{\mathrm{H}_{2} \mathrm{O}}^{*}$ & $=K_{\mathrm{H}_{2} \mathrm{O}} p_{\mathrm{H}_{2} \mathrm{O}} \Theta^{*}$ \\
\hline
\end{tabular}


Using the quasi equilibrium assumption (QEA) for the fast reactions, one can calculate the reaction rates for the $\mathrm{CO}$-hydrogenation, $\mathrm{CO}_{2}$-hydrogenation and the reverse-water-gas shift reaction as follows

$$
\begin{aligned}
r_{\mathrm{CO}} & =k_{1}\left(p_{\mathrm{CO} p_{\mathrm{H}_{2}}^{2}}^{2}-\frac{p_{\mathrm{CH}_{3} \mathrm{OH}}}{K_{\mathrm{P}_{1}}}\right) \Theta^{\odot} \Theta^{\otimes} \\
r_{\mathrm{CO}_{2}} & =k_{2}\left(p_{\mathrm{CO}_{2}} p_{\mathrm{H}_{2}}-\frac{p_{\mathrm{CH}_{3} \mathrm{OH}} p_{\mathrm{H}_{2} \mathrm{O}}}{K_{\mathrm{P}_{2}} p_{\mathrm{H}_{2}}^{2}}\right) \Theta^{*^{2}} \Theta^{\odot} \\
r_{R W G S} & =k_{3}\left(p_{\mathrm{CO}_{2}}-\frac{p_{\mathrm{CO} p_{\mathrm{H}_{2} \mathrm{O}}}}{K_{\mathrm{P}_{3} p_{\mathrm{H}_{2}}}}\right) \Theta^{\otimes} \Theta^{*} .
\end{aligned}
$$

Here partial pressures are used instead of fugacities, which is justified by the fact that fugacity coefficients are close to one for the operating conditions considered in this paper (Vollbrecht, 2007). The corresponding surface coverages are given by

$\Theta^{\odot}=(1+\underbrace{K_{\mathrm{CO}}}_{\beta_{8}} p_{\mathrm{CO}}+\underbrace{\left(K_{\mathrm{A} 3} K_{\mathrm{CO}} K_{\mathrm{H}_{2}}^{3 / 2}\right)}_{\beta_{9}} p_{\mathrm{H}_{2}}^{3 / 2} p_{\mathrm{CO}}+\underbrace{K_{\mathrm{CH}_{3} \mathrm{OH}}^{\odot}}_{\beta_{10}} p_{\mathrm{CH}_{3} \mathrm{OH}}+\underbrace{K_{\mathrm{CO}_{2}}}_{\beta_{11}} p_{\mathrm{CO}_{2}})^{-1}$

$$
\begin{aligned}
& \Theta^{\otimes}=(1+\underbrace{\sqrt{K_{\mathrm{H}_{2}}}}_{\beta_{7}} \sqrt{p_{\mathrm{H}_{2}}})^{-1} \\
& \Theta^{*}=(1+\underbrace{\frac{K_{\mathrm{H}_{2} \mathrm{O}}}{K_{\mathrm{B} 8} K_{\mathrm{B} 9} K_{\mathrm{H}_{2}}}}_{\beta_{13}} \frac{p_{\mathrm{H}_{2} \mathrm{O}}}{p_{\mathrm{H}_{2}}}+\underbrace{\frac{K_{\mathrm{CH}_{3} \mathrm{OH}}^{*}}{K_{\mathrm{B} 5} K_{\mathrm{H}_{2}}^{1 / 2}}}_{\beta_{16}} \frac{p_{\mathrm{CH}_{3} \mathrm{OH}}}{p_{\mathrm{H}_{2}}^{1 / 2}}+\underbrace{K_{\mathrm{CH}_{3} \mathrm{OH}}^{*}}_{\beta_{14}} p_{\mathrm{CH}_{3} \mathrm{OH}} \\
& +\underbrace{\frac{K_{\mathrm{H}_{2} \mathrm{O}}}{K_{\mathrm{B} 9} K_{H_{2}}^{1 / 2}}}_{\beta_{15}} \frac{p_{\mathrm{H}_{2} \mathrm{O}}}{p_{\mathrm{H}_{2}}^{1 / 2}}+\underbrace{K_{\mathrm{H}_{2} \mathrm{O}}}_{\beta_{12}} p_{\mathrm{H}_{2} \mathrm{O}})^{-1}
\end{aligned}
$$


Therein, a reparametrization is introduced as indicated with the lumped $\beta_{i}$ parameters, which have to be fitted to experimental data. A known problem for the parameter estimation is the correlation between frequency factor and activation energy, which impedes reasonable results. Therefore, the following reformulation of the Arrhenius-equation is used (Schwaab et al. 2008; Schwaab and Pinto, 2007; Xu and Froment, 1989):

$$
k_{i}=\exp (\underbrace{A}_{\beta_{1}, \beta_{3}, \beta_{5}}-\underbrace{B}_{\beta_{2}, \beta_{4}, \beta_{6}}\left(\frac{T_{\mathrm{ref}}}{T}-1\right))
$$

with reference temperature $T_{\text {ref }}=523.15 \mathrm{~K}$ and equilibrium constants according to Vollbrecht (2007).

The temperature dependency of the adsorption equilibrium constants is much weaker compared to the reaction rate constants and is therefore neglected (Vollbrecht, 2007). Nevertheless, the overall number of parameters is relatively high leading to identifiability problems as indicated in Vollbrecht (2007). Therefore also simplified Langmuir-Hinshelwood kinetics will be introduced in the next paragraph.

\subsection{Simplified Langmuir-Hinshelwood Kinetic Model}

The simplified Langmuir-Hinshelwood kinetics is not based on elementary reaction steps but on lumped reaction kinetics for reactions Eqs. (1)-(3) of the methanol synthesis. This leads to the following simplified reaction rate expressions:

$$
\begin{aligned}
r_{\mathrm{CO}} & =k_{1} p_{\mathrm{CO}} p_{\mathrm{H}_{2}}^{2}\left(1-\frac{1}{K_{\mathrm{P} 1}} \frac{p_{\mathrm{CH}_{3} \mathrm{OH}}}{p_{\mathrm{CO}} p_{\mathrm{H}_{2}}^{2}}\right) \Theta^{\odot} \Theta^{\otimes^{4}} \\
r_{\mathrm{CO}_{2}} & =k_{2} p_{\mathrm{CO}_{2}} p_{\mathrm{H}_{2}}^{2}\left(1-\frac{1}{K_{\mathrm{P} 2}} \frac{p_{\mathrm{CH}_{3} \mathrm{OH}} p_{\mathrm{H}_{2} \mathrm{O}}}{p_{\mathrm{CO}_{2}} p_{\mathrm{H}_{2}}^{3}}\right) \Theta^{*^{2}} \Theta^{\otimes^{4}} \\
r_{R W G S} & =k_{3} p_{\mathrm{CO}_{2}}\left(1-\frac{1}{K_{\mathrm{P} 3}} \frac{p_{\mathrm{CO}} p_{\mathrm{H}_{2} \mathrm{O}}}{p_{\mathrm{CO}_{2}} p_{\mathrm{H}_{2}}}\right) \Theta^{*} \Theta^{\odot}
\end{aligned}
$$


The corresponding surface coverages are:

$$
\begin{aligned}
& \Theta^{\odot}=(1+\underbrace{K_{\mathrm{CO}}}_{\beta_{11}} p_{\mathrm{CO}}+\underbrace{K_{\mathrm{CH}_{3} \mathrm{OH}}^{\odot}}_{\beta_{12}} p_{\mathrm{CH}_{3} \mathrm{OH}}+\underbrace{K_{\mathrm{CO}_{2}}^{\odot}}_{\beta_{14}} p_{\mathrm{CO}_{2}})^{-1} \\
& \Theta^{\otimes}=(1+\underbrace{\sqrt{K_{\mathrm{H}_{2}}}}_{\beta_{7}} \sqrt{p_{\mathrm{H}_{2}}})^{-1} \\
& \Theta^{*}=(1+\underbrace{\frac{K_{\mathrm{H}_{2} \mathrm{O}} K_{\mathrm{O}}}{K_{\mathrm{H}_{2}}}}_{\frac{\beta_{10} \beta_{9}}{\beta_{7}^{2}}} \frac{p_{\mathrm{H}_{2} \mathrm{O}}}{p_{\mathrm{H}_{2}}}+\underbrace{K_{\mathrm{CO}_{2}}}_{\beta_{13}} p_{\mathrm{CO} 2}+\underbrace{K_{\mathrm{CH}_{3} \mathrm{OH}}^{*}}_{\beta_{8}} p_{\mathrm{CH}_{3} \mathrm{OH}}+\underbrace{K_{\mathrm{H}_{2} \mathrm{O}}}_{\beta_{9}} p_{\mathrm{H}_{2} \mathrm{O}})^{-1}
\end{aligned}
$$

This reduces the problem to a total number of 14 unknown parameters, which are 6 unknown parameters for the reaction rate constants according to Eq. 10 and another 8 unknown adsorption constants.

As a consequence of the lumping procedure, $\Theta^{\otimes}$ appears with high exponents in the above reaction rate expressions, which could lead to unrealistic high sensitivity to the hydrogen partial pressure. This increased sensitivity, however, is not effective if the reactor is operated with hydrogen in excess, leading to almost constant value of $\Theta^{\otimes}$. This is the typical situation in practice, which will also be considered in the present study.

\subsection{Extension to Variable Number of Reduced and Oxidized Surface Centers}

So far, a fixed amount of reduced and oxidized surface centers was considered. But this assumption does not explain transient effects after changes in the feed gas composition as described for example in the work of Choi et al. (2001a b); Muhler et al. (1994); Nakamura et al. (2003); Peter et al. (2012); Vollbrecht (2007). Therefore in a second step, conversion of oxidized surface centers to reduced surface centers and vice versa is taken into account leading to morphological changes on the catalyst surface. The assumption that the total 
number of oxidized and reduced surface centers is constant is relaxed and replaced by the more general assumption that the sum of all oxidized and reduced surface centers is constant according to:

$$
\underbrace{\sum_{i}^{N} \odot_{i}}_{\text {oxidized centers }}+\underbrace{\sum_{j}^{M} *_{j}}_{\text {reduced centers }}=\text { constant }=1
$$

It is a well known fact that the ratio of oxidized to reduced centers is influenced by the gas composition (Nakamura et al., 2003). $\mathrm{CO}$ and $\mathrm{H}_{2}$ show reducing properties and on the other side $\mathrm{CO}_{2}$ and $\mathrm{H}_{2} \mathrm{O}$ are oxidizing components. This causes a reduction of the catalyst while facing $\mathrm{CO}$ and $\mathrm{H}_{2}$ and an oxidation if facing $\mathrm{CO}_{2}$ and $\mathrm{H}_{2} \mathrm{O}$

$$
\begin{aligned}
\mathrm{H}_{2}+\odot_{\mathrm{i}} & \rightleftharpoons \mathrm{H}_{2} \mathrm{O}+*_{\mathrm{i}}, \\
\mathrm{CO}+\odot_{\mathrm{i}} & \rightleftharpoons \mathrm{CO}_{2}+*_{\mathrm{i}} .
\end{aligned}
$$

Experiments showed that $\mathrm{Cu}$ particles on the catalyst are flat under reducing and more spherical under oxidizing conditions as shown in Fig. 1 Grunwaldt 135 et al. 2000, Nakamura et al. 2003).

At steady state, reactions 18 and $(19)$ are in equilibrium according to

$$
\begin{aligned}
& K_{1}=\frac{p_{\mathrm{H}_{2} \mathrm{O}}}{p_{\mathrm{H}_{2}}} \cdot \frac{\phi}{1-\phi}, \\
& K_{2}=\frac{p_{\mathrm{CO}_{2}}}{p_{\mathrm{CO}}} \cdot \frac{\phi}{1-\phi},
\end{aligned}
$$

where $\phi$ represents the total amount of reduced centers and $1-\phi$ the total amount of oxidized centers. Following Ovesen et al. (1997), $\phi$ can be calculated from the equilibrium relations as follows

$$
\phi=\frac{1}{2}\left(1-\frac{\gamma^{*}}{\gamma_{0}}\right)
$$




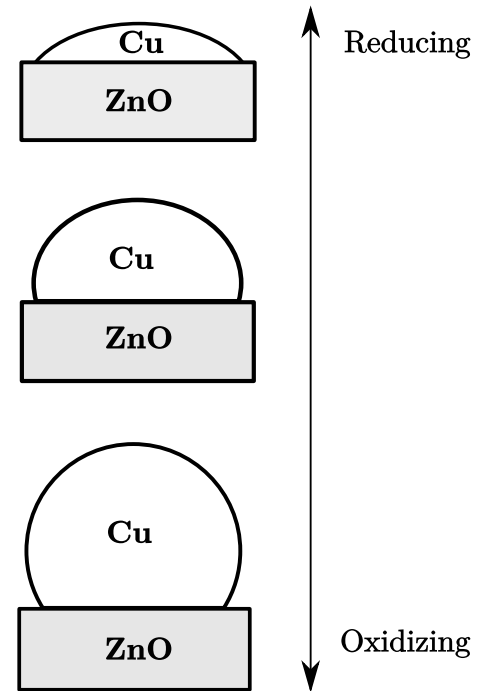

Figure 1: A scheme of the morphology effect at the catalyst surface. While facing a gas environment with a reduction potential $\left(\mathrm{CO} \& \mathrm{H}_{2}\right)$ a wetting effect occurs, which results in $\mathrm{Cu}$ $\mathrm{ZnO}$ alloy (Fujitani and Nakamura 1998) and a more active catalyst for CO-hydrogenation. Facing gas with oxidizing potential $\left(\mathrm{CO}_{2} \& \mathrm{H}_{2} \mathrm{O}\right)$, the $\mathrm{Cu}$-particle become more spherical and more active for $\mathrm{CO}_{2}$-hydrogenation.

with

$$
\frac{\gamma^{*}}{\gamma_{0}}=\frac{1-\sqrt{K_{1} K_{2} \frac{p_{\mathrm{H}_{2}} p_{\mathrm{CO}}}{p_{\mathrm{H}_{2} \mathrm{O}} p_{\mathrm{CO}}}}}{1+\sqrt{K_{1} K_{2} \frac{p_{\mathrm{H}_{2}} p_{\mathrm{CO}}}{p_{\mathrm{H}_{2}} p_{\mathrm{CO}_{2}}}}} .
$$

The ratio in $\frac{\gamma^{*}}{\gamma_{0}}$ is the relative free energy contact surface of $\mathrm{Cu}$ and $\mathrm{Zn}$ (see Fig. 1) (Ovesen et al., 1997, Vesborg et al., 2009). It can be related to the catalyst morphology using the Wulff construction framework (Clausen et al. 1994 Wulff, 1901). The equilibrium constants $K_{1}$ and $K_{2}$ (Eq. 20) \& (21)) can be expressed as a function of free energy according to

$$
\begin{aligned}
& K_{1}=\frac{k_{1}^{+}}{k_{1}^{-}}=\exp \left(\frac{-\Delta G_{1}}{R T}\right), \\
& K_{2}=\frac{k_{2}^{+}}{k_{2}^{-}}=\exp \left(\frac{-\Delta G_{2}}{R T}\right) .
\end{aligned}
$$

With $\phi$ from Eqs. $200-22$ the kinetic equations from the previous section 
assuming a constant amount of reduced and oxidized centers can be reformulated for a variable number of reduced and oxidized centers by replacing $\Theta^{\odot}$ and $\Theta^{*}$ in Equations (4)- (6), or (11)-(13), respectively, with $\tilde{\Theta}^{\odot}$ and $\tilde{\Theta}^{*}$ from the following 145 relations.

$$
\begin{aligned}
\tilde{\Theta}^{\odot} & =(1-\phi) \cdot \Theta^{\odot}, \\
\tilde{\Theta}^{*} & =\phi \cdot \Theta^{*} .
\end{aligned}
$$

Here, $\Theta^{\odot}$ and $\Theta^{*}$ are the amounts of free oxidized and reduced surface centers relative to the corresponding total amounts of oxidized and reduced surface centers. Whereas, $1-\phi$ and $\phi$ are the total amounts of oxidized and reduced surface centers relative to the constant total amount of oxidized plus reduced surface centers considered in this section. In the remainder, $\tilde{\Theta}^{\odot}, \tilde{\Theta}^{*}$ will be used exclusively for the detailed and the simplified kinetics to account for variable number of oxidized and reduced surface centers.

Under transient conditions, reaction equilibrium according to Eqs. 20121] is not valid anymore. Experiments have shown characteristic methanol overshoots after switching between different gas compositions (Vesborg et al. 2009: Wilmer and Hinrichsen, 2002). Therefore, under transient conditions Eq. 22 has to be replaced by the corresponding kinetic equation

$$
\begin{aligned}
\frac{d \phi}{d t} & =k_{1}^{+}\left(y_{\mathrm{H}_{2}}(1-\phi)-\frac{1}{K_{1}} y_{\mathrm{H}_{2} \mathrm{O}} \phi\right) \\
& +k_{2}^{+}\left(y_{\mathrm{CO}}(1-\phi)-\frac{1}{K_{2}} y_{\mathrm{CO}_{2}} \phi\right) .
\end{aligned}
$$

Additional rate constants $k_{1}^{+}, k_{2}^{+}$are fitted to transient data.

\section{Experiments and Parameter Estimation}

For the parameter estimation, 140 stationary experiments reported in Vollbrecht (2007) were used. The experimental setup is based on a modified, differential CSTR of a Micro-Berty Reactor type described Berty (1999). Dosing 
of feed gases was realized by mass flow controllers and a set of valves to enable stationary and dynamic mode of operation. A commercial synthesis catalyst 165 (BASF S3-86) was used in a crushed form to overcome mass transfer limitations. The temperature was varied in the range from 503.15 to $533.15 \mathrm{~K}$ and the pressure in the range from 30 to 60 bar. Furthermore, the ratio of $\mathrm{CO}$ to $\mathrm{CO}_{2}$ was varied over the full range from pure $\mathrm{CO}$ to pure $\mathrm{CO}_{2}$. For the interested reader, all stationary experimental conditions and results are summarized in the supplementary material of the paper. The chemical analysis of feed gases and product gases was performed by a gas chromatographic setup. Order to reduce the influence of measurement uncertainties, a balancing of the analytical results was performed prior to the parameter estimation. In addition to the comprehensive set of steady state experiments, dynamic experiments with 175 step changes between CO feed $\left(y_{\mathrm{CO}}=12.6 \%, y_{\mathrm{H}_{2}}=72.2 \%\right.$ and $\left.y_{\mathrm{N}_{2}}=16.0 \%\right)$, and $\mathrm{CO}_{2}$ feed $\left(y_{\mathrm{CO}_{2}}=11.9 \%, y_{\mathrm{H}_{2}}=71.5 \%\right.$ and $\left.y_{\mathrm{N}_{2}}=16.6 \%\right)$ with constant temperature $T=523.15 \mathrm{~K}$, pressure $p=50$ bar and constant space velocity $\dot{V}=240 \mathrm{ml}^{\mathrm{N}} / \mathrm{min}$ were presented by Vollbrecht (2007).

The dynamic experiments were used to estimate the kinetic parameters $k_{1}^{+}$ and $k_{2}^{+}$in Eq. 28 . All other parameters $\beta_{i}$ were fitted to the steady state data. At steady state, the experimental reaction rates $R_{i, \exp }$ can be calculated from the measured in- and output mole fractions $y_{i, 0}$ and $y_{i}$ according to

$$
R_{i, \exp }=-\left(y_{i, 0}-y_{i} \gamma\right) \frac{p_{N} \dot{V}_{N}}{R T_{N} m_{k a t}}
$$

with volume contraction $\gamma$, which was derived by the change of fraction of $\mathrm{N}_{2}$ in the gas at the in- and output. Using the reaction rates $R_{i, \text { exp }}$, parameters $\beta_{i}$ are determined from the solution of a nonlinear least squares problem according to

$$
\min _{\forall \beta_{i}}\left(\sum_{i=1}^{N}\left(R_{i, \exp }-\sum_{j=1}^{3} \nu_{i j} r_{j}\right)^{2}\right) .
$$


with $r_{j}$ from Eqs. (4)-(6) for the detailed kinetics and Eqs. (11)-(13) for the simplified kinetics and stoichiometric coefficients from Table 4.

\begin{tabular}{lccc} 
Table 4: & \multicolumn{4}{c}{ Stoichiometric matrix of main reactio } \\
\hline Species & $r_{C O}$ & $r_{C O_{2}}$ & $r_{R W G S}$ \\
\hline $\mathrm{CO}$ & -1 & 0 & 1 \\
$\mathrm{CO}_{2}$ & 0 & -1 & -1 \\
$\mathrm{H}_{2}$ & -2 & -3 & -1 \\
$\mathrm{CH}_{3} \mathrm{OH}$ & 1 & 1 & 0 \\
$\mathrm{H}_{2} \mathrm{O}$ & 0 & 1 & 1 \\
\hline
\end{tabular}

Since local optimization methods do not give satisfying results due to mul-

tiple local minima, deterministic global optimization with BARON

(Tawarmalani and Sahinidis, 2005) in GAMS (Gam, 2013) is applied. BARON uses a branch and bound algorithm with over- and underestimators to prove global optimality.

In a first separate step, $\Delta G_{1}$ and $\Delta G_{2}$ are fitted to the experimental data using Eqs. 201-23) and the measured values of the partial pressures of $\mathrm{CO}$, $\mathrm{CO}_{2}, \mathrm{H}_{2}$ and $\mathrm{H}_{2} \mathrm{O}$. The global optimum obtained from BARON is

$$
\begin{aligned}
& \Delta G_{1}=1.1348 \times 10^{3} \mathrm{~J} \mathrm{~mol}^{-1} \\
& \Delta G_{2}=-0.7693 \times 10^{3} \mathrm{~J} \mathrm{~mol}^{-1} .
\end{aligned}
$$

The amount $\phi$ of reduced sites of every experiment calculated with these values is illustrated in Fig. 2. The experiments 80-140 containing only CO and $\mathrm{H}_{2}$ in the feed result in a catalyst with $\phi$ close to one. With increasing amount of $\mathrm{CO}_{2}$ and $\mathrm{H}_{2} \mathrm{O}$ the fraction of reduced centers decreases.

For the estimation of the remaining parameters the steady state experiments were divided into three subsets:

1. only CO-Feed (experiment 80-140), which can be used to estimate $\mathrm{r}_{\mathrm{CO}}$, because all other reactions are suppressed. 


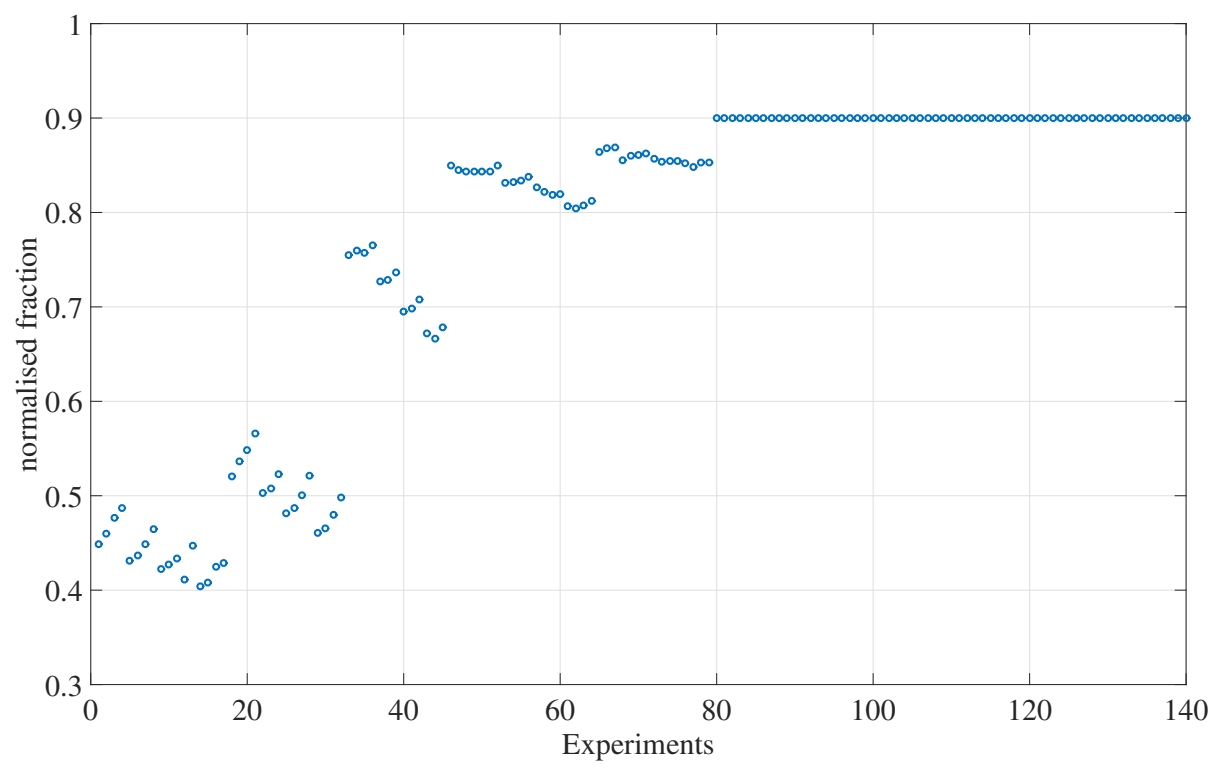

Figure 2: Fraction of reduced centers $\phi$ on the catalyst surface for all 140 steady state experiments. 1 for a full reduced catalyst and 0 for a complete oxidized catalyst. Estimated using the Wulff-construction framework 20]-23.

2. mixed Feed $\left(\mathrm{CO}\right.$ and $\left.\mathrm{CO}_{2}\right)$ (experiment 33-79), which is used to estimate $\mathrm{r}_{\mathrm{CO}_{2}}$.

3. only $\mathrm{CO}_{2}$-Feed (experiment 1-32), which is used to estimate the remaining parameter for $\mathrm{r}_{\mathrm{RWGS}}$.

For each subset, a nonlinear least squares problem 30 is solved using the results from the previous step. Results will be discussed in the next section.

For the parameter identification only two of the component balances are necessary, because the rank of the stoichiometric matrix (Tab. 4) equals two. But more than two balances may improve the results and minimize the effect of measurement errors. The highest accuracy for the analytical determination of the composition has been reached by the use of a Flame Ionization Detector (FID) for the carbon-containing components. For this reason, only carbon-containing component balances ( $\mathrm{R}_{\mathrm{CO}}, \mathrm{R}_{\mathrm{CO}_{2}}$ and $\mathrm{R}_{\mathrm{CH}_{3} \mathrm{OH}}$ ) were used. As pointed out above, dynamic experiments were used to fit the kinetic constants $k_{1}^{+}, k_{2}^{+}$from 
Eq. (28). For this purpose, the dynamic reactor equations from Vollbrecht (2007) were used to calculate the trajectories of the mole fractions $y_{i}$

$$
\dot{y}_{i}=Z\left[\frac{1}{\tau} y_{i, 0}-\left(\frac{1}{\tau}+\frac{1}{\kappa} \sum_{i=1}^{N_{K}} \sum_{j=1}^{N_{R}} \nu_{i j} r_{j}\right) y_{i}+\frac{1}{\kappa} \sum_{j=1}^{N_{R}} \nu_{i j} r_{j}\right] .
$$

For the dynamic transient behavior, it was found that the accumulation on the catalyst surface should be taken into account (Vollbrecht, 2007). In this case the specific amount of surface centers $q_{\text {sat }}$ has to be considered that extends the reaction terms to:

$$
m_{\mathrm{kat}} \sum_{j=1}^{N_{R}} \nu_{i j} r_{j}=m_{\mathrm{kat}} \cdot q_{\mathrm{sat}} \sum_{j=1}^{N_{R}} \sum_{e=1}^{N_{E S, j}} \nu_{i j}^{(e)} r_{j}^{(e)} .
$$

Furthermore the dynamic change in the surface coverage for each species can be calculated by:

$$
\frac{d \Theta_{s}}{d t}=\sum_{i=1}^{N_{K}} \frac{\partial \Theta_{i}}{\partial p_{i}} \frac{d p_{i}}{d t}=\sum_{j=1}^{N_{R}} \sum_{e=1}^{N_{E S, j}} \nu_{i j}^{(e)} r_{j}^{(e)}
$$

with $\Theta_{i}$ as the Langmuir Adsorption Isotherm of component i. Eq. 34 ) and (35) can be used to extend the dynamic equation of the CSTR (Eq. (33)) and leads to this system of ordinary differential equations:

$$
M(t, y) \cdot \frac{d y}{d t}=f(t, y)
$$

which can be solved numerically. Another nonlinear least squares problem was solved in terms of the mole fractions of the different components at different time point according to

$$
\min _{k_{1}, k_{2}} \sum_{k} \sum_{i}\left(y_{i, \exp }\left(t_{k}\right)-y_{i}\left(t_{k}\right)\right)^{2}
$$

including components $\mathrm{CO}, \mathrm{CO}_{2}$ and $\mathrm{CH}_{3} \mathrm{COH}$ for $t>140 \mathrm{~min}$.

This dynamic optimization problem was solved in MATLAB (MATLAB 2014) using the TOMLAB toolbox (Holmstroem, 1997). 


\section{Results}

\subsection{Detailed Model}

The results for the detailed kinetics are shown in Fig. 3 in terms of mole fractions of the different components. In all cases, the theoretical results nicely fit the experiments.
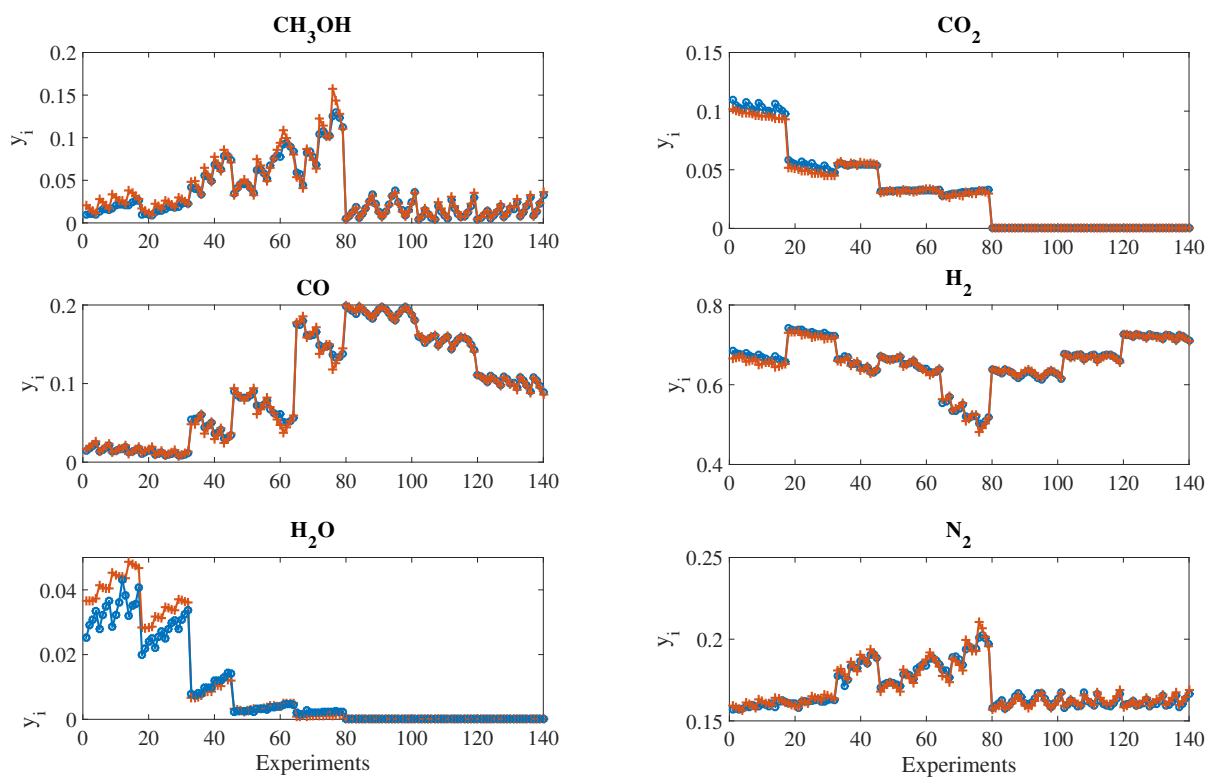

Figure 3: Results of stationary experiments compared to simulation with the detailed model and variable $\phi$ for all 6 species. Blue marker denote experimental data and red marker show simulation results.

The estimated parameters are summarized in Tab. 5. The Profile-Likelihood method was used to check for structural identifiability (Raue et al. 2010$)$, i.e. to check whether the parameters can be determined uniquely from the available measurement information. Compared to other methods the computational effort is moderate. Each parameter is varied individually, while rerunning the parameter estimation and tracking the resulting objective value over the varied parameter. The parameter is structural identifiable, if its change has an impact 
on the value of the objective function and produces a unique minimum. Application to the detailed model reveals, that parameters $\beta_{7}, \beta_{12}$ and $\beta_{13}$ are not structural identifiable. This results in very slow convergence of the optimiza-

240 tion, which was terminated after $24 \mathrm{~h}$. It is further observed that some of the $\beta$ parameters are zero, namely $\beta_{8}, \beta_{10}, \beta_{14}-\beta_{16}$. A physical interpretation is not possible due to reparametrization. For example, $\beta_{12}=0$ implies that the adsorption constant of water is zero. This would also require $\beta_{13}$ to be zero, which is not observed in Table 5 . Nevertheless, the experimental data could be fitted

245 quite well. For comparison we show the results, which were obtained using the well known vanden Bussche and Froment kinetics (Bussche and Froment, 1996) in Fig. 4. Since CO-hydrogenation is neglected in this model, experiments 80-140 with pure CO feed can not be reproduced. Further, larger deviations are also observed in the other experiments. These could certainly be reduced by refitting the kinetics to the present experimental data, which however, was beyond the scope of the present study.

In general, two approaches are possible to improve identifiability. The first is to include additional independent measurement information. The second is to simplify the model to reduce the number of unknown parameters. Since the 255 first is challenging in the present case, we followed the second approach. Results are discussed in the next section.

\subsection{Simplified Model}

The parameter estimation was also done for the simplified kinetic model Eq. (11) - 13). The results are illustrated in Fig. 5. It is concluded that the simple model fits the experimental results almost equally well compared to the detailed model.

The estimated parameters are also listed in Tab. 5. It was shown with the Profile-Likelihood method that structural identifiability has improved compared to the detailed model. Only parameters $\beta_{9}$ and $\beta_{10}$ show flat optima. Nevertheless, all optimization runs converged within the given time and tolerances to global optimality. The first 6 parameters in Tab. 5 have the same physical 

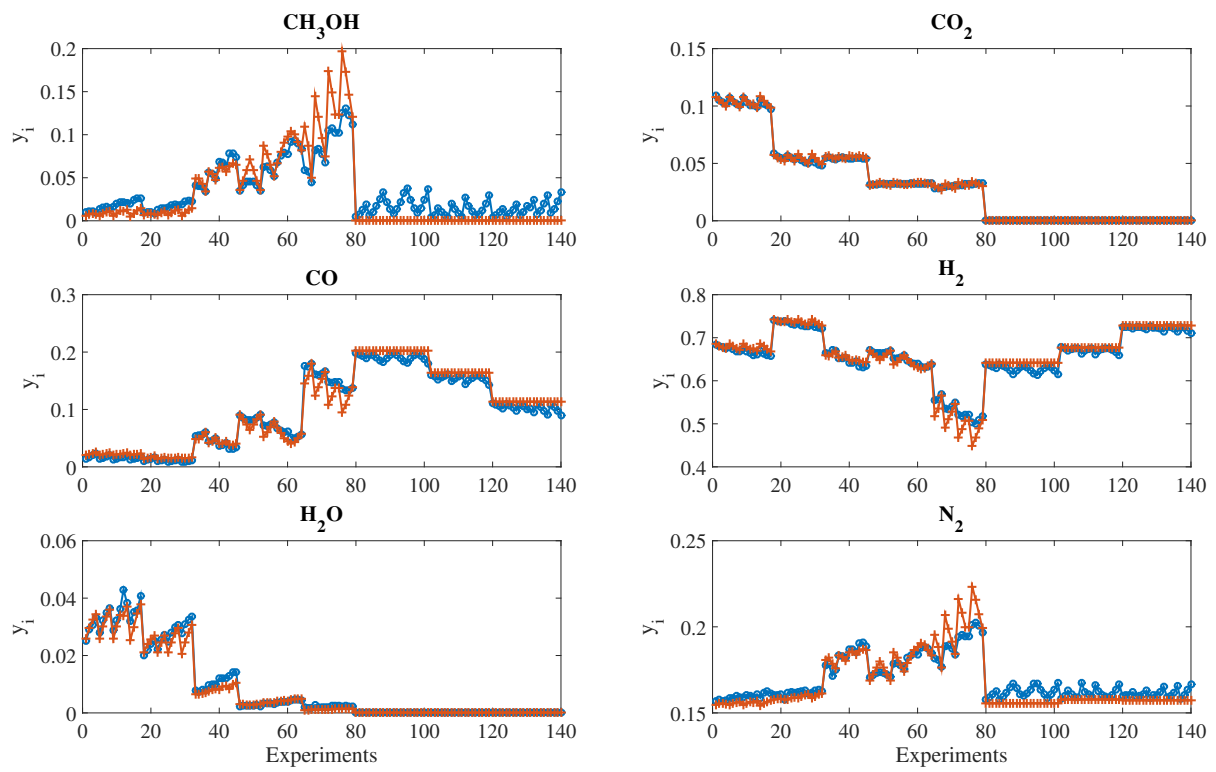

Figure 4: Results of stationary experiments compared to simulation with vanden Bussche/Froment kinetic model. Blue marker denote experimental data and red marker show simulation results.

meaning for both models and are therefore in the same range. The other parameters have different physical meaning and should not be compared one to one between detailed and simplified kinetics. $\beta_{8}$ and $\beta_{12}$ are equal to zero, which consistently implies that the product methanol is spontaneously desorbed. Further, the adsorption rate constant of $\mathrm{CO}_{2}$ in this model $\left(\beta_{13}, \beta_{14}\right)$ is close to zero.

\subsection{Dynamic Experiments}

Finally, the simplified model was also compared to dynamic experimental data as illustrated in Fig. 6. The simplified model was either used with quasistatic $\phi$ from Eq. 22 or dynamic $\phi$ from Eq. 28). For dynamic $\phi$, the additional rate constants $k_{1}^{+}$and $k_{2}^{+}$were fitted to the experimental data. The values are listed in Table 6. The Profile-Likelihood method was used to test for structural identifiability. 

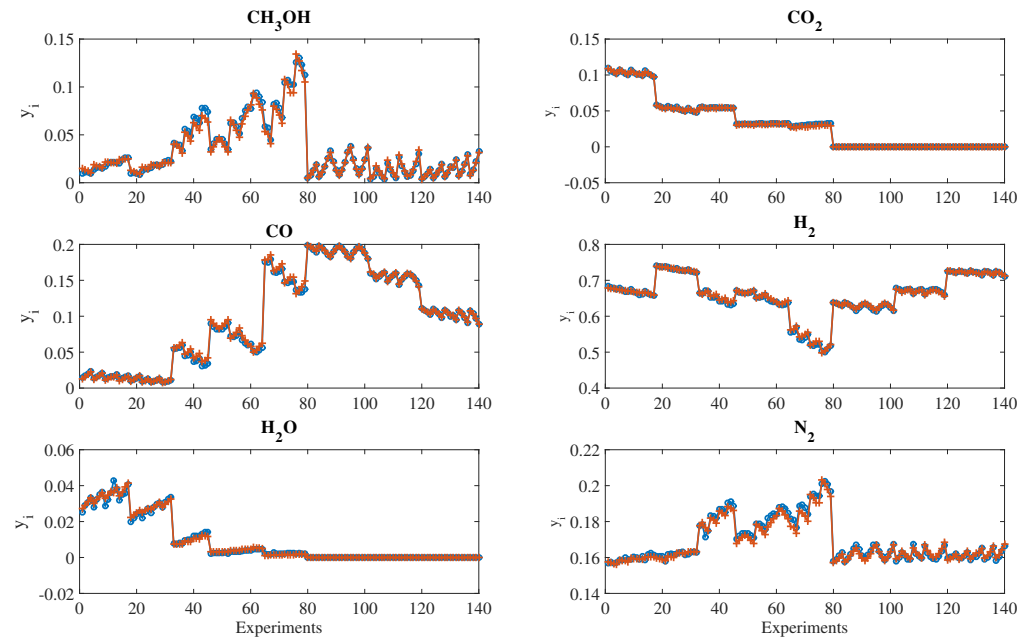

Figure 5: Results of stationary experiments compared to simulation with simplified kinetic model and variable $\phi$. Blue marker denote experimental data and red marker show simulation results.

280 can be caused by remaining $\mathrm{CO}_{2}$ in the CSTR due to the noticeable residence time. After another 70 minutes, the feed is switched again to pure $\mathrm{CO}_{2}$ and the previous pattern is repeated. 
Table 5: List of estimated parameters for the detailed Eq. 44-(9) and simplified model Eq. 111)- (16) using Global optimization.

\begin{tabular}{|c|c|c|c|c|}
\hline $\begin{array}{l}\text { Unknown } \\
\text { parameter }\end{array}$ & $\begin{array}{l}\text { Estimated } \\
\text { detailed model }\end{array}$ & Units & $\begin{array}{l}\text { Estimated } \\
\text { simplified model }\end{array}$ & Units \\
\hline$\beta_{1}$ & -10.2630 & - & -4.7636 & - \\
\hline$\beta_{2}$ & 25.9620 & - & 26.1883 & - \\
\hline$\beta_{3}$ & -5.9727 & - & -3.4112 & - \\
\hline$\beta_{4}$ & 3.0027 & - & 3.4470 & - \\
\hline$\beta_{5}$ & -5.2746 & - & -5.7239 & - \\
\hline$\beta_{6}$ & 23.1523 & - & 23.4744 & - \\
\hline$\beta_{7}$ & 1.2634 & $\operatorname{bar}^{-1 / 2}$ & 1.1665 & $\operatorname{bar}^{-1 / 2}$ \\
\hline$\beta_{8}$ & 0 & $\operatorname{bar}^{-1}$ & 0 & $\operatorname{bar}^{-1}$ \\
\hline$\beta_{9}$ & $2.049 \times 10^{-3}$ & $\operatorname{bar}^{-5 / 2}$ & 0.0297 & bar $^{-1}$ \\
\hline$\beta_{10}$ & 0 & $\operatorname{bar}^{-1}$ & $1.60 \times 10^{3}$ & - \\
\hline$\beta_{11}$ & 0.1366 & $\operatorname{bar}^{-1}$ & 0.1470 & bar $^{-1}$ \\
\hline$\beta_{12}$ & 0.0517 & $\operatorname{bar}^{-1}$ & 0 & $\operatorname{bar}^{-1}$ \\
\hline$\beta_{13}$ & 38.6097 & - & 0.04712 & $\operatorname{bar}^{-1}$ \\
\hline$\beta_{14}$ & 0 & $\operatorname{bar}^{-1}$ & 0 & bar $^{-1}$ \\
\hline$\beta_{15}$ & 0 & $\operatorname{bar}^{-1 / 2}$ & - & - \\
\hline$\beta_{16}$ & 0 & $\operatorname{bar}^{-1 / 2}$ & - & - \\
\hline
\end{tabular}
Eq. 28 is able to reproduce the experiments quite well, whereas the simplified model with a quasistatic $\phi$ from Eq. 28 neglects the lag of the catalyst and is therefore not suitable to describe the transient behavior.

\section{Conclusion}

In the present paper novel Langmuir-Hinshelwood kinetics for methanol production from $\mathrm{CO}, \mathrm{CO}_{2}$ and $\mathrm{H}_{2}$ using conventional $\mathrm{Cu} / \mathrm{ZnO} / \mathrm{Al}_{2} \mathrm{O}_{3}$ catalysts were proposed. The models account for hydrogenation of $\mathrm{CO}_{2}$ and $\mathrm{CO}$ and 

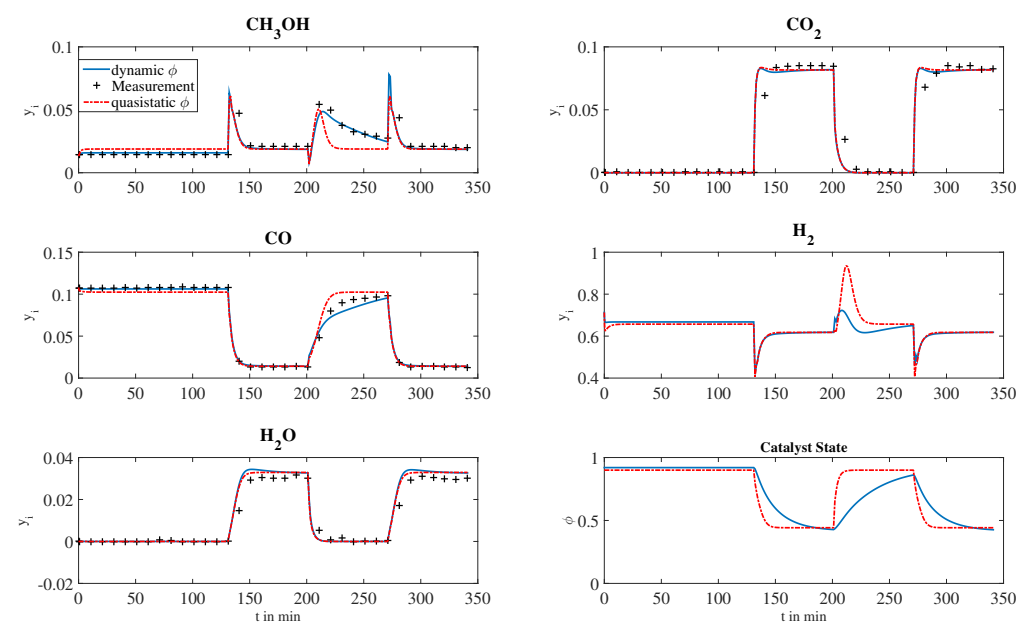

Figure 6: Output of the dynamic experiment compared to the simplified model with quasistatic and dynamic $\phi$ with surface accumulation. Black marker denote experimental data, blue lines show the simulation results for dynamic $\phi$ and the red dotted line show simulation results for quasistatic $\phi$.

different active centers on the catalyst surface, which can change depending on the reaction conditions. The models show good agreement with steady state and dynamic data over a wide range of $\mathrm{CO}$ to $\mathrm{CO}_{2}$ ratios in the feed. They are therefore suitable for methanol production under changing feed conditions employed for example in novel applications for chemical energy storage. Global optimization is used for parameter identification and structural identifiability was discussed critically leading to a simplified model with improved structural identifiability, which describes the experimental data almost equally well compared to a detailed model. It therefore builds a suitable basis for future work on model based design and control of methanol reactors for chemical energy storage under strongly varying conditions. 
Table 6: Estimated Parameter for catalyst ODE (Eq. (33) using the dynamic experimental data of (Vollbrecht 2007) and the previously estimated equilibrium constants Eq. 24) and 25.

\begin{tabular}{lll}
\hline Unknown parameter & Estimated value & Units \\
\hline$k_{1}^{+}$ & $4.06 \times 10^{-4}$ & $\mathrm{~s}^{-1}$ \\
$k_{2}^{+}$ & $3.94 \times 10^{-4}$ & $\mathrm{~s}^{-1}$ \\
\hline
\end{tabular}

\section{References}

\section{References}

(2013). GAMS - A User's Guide, GAMS Release 24.2.1. GAMS Development Corporation, Washington, DC, USA.

Asinger, F. (1986). Methanol - Chemie und Energierohstoff. Springer.

Berty, J. M. (1999). Experiments in catalytic reaction engineering, volume 124. Elsevier.

Bussche, K. M. V. and Froment, G. F. (1996). A steady-state kinetic model for methanol synthesis and the water gas shift reaction on a commercial $\mathrm{Cu} / \mathrm{ZnO} / \mathrm{Al}_{2} \mathrm{O}_{3}$ catalyst. Journal of Catalysis, 161(1):1-10.

Chinchen, G. C., Denny, P. J., Parker, D. G., Spencer, M. S., and Whan, D. A. (1987). Mechanism of methanol synthesis from $\mathrm{CO}_{2} / \mathrm{CO} / \mathrm{H}_{2}$ mixtures over copper/zinc oxide/alumina catalysts: use of ${ }^{14} \mathrm{C}$-labelled reactants. Applied Catalysis, 30(2):333-338.

Chinchen, G. C., Mansfield, K., and Spencer, M. S. (1990). The methanol synthesis: How does it work. Chemtech, 20(11):692-699.

Choi, Y., Futagami, K., Fujitani, T., and Nakamura, J. (2001a). The difference in the active sites for $\mathrm{co} 2$ and co hydrogenations on $\mathrm{cu} /$ zno-based methanol synthesis catalysts. Catalysis letters, 73(1):27-31. 
Choi, Y., Futagami, K., Fujitani, T., and Nakamura, J. (2001b). The role of $\mathrm{ZnO}$ in $\mathrm{Cu} / \mathrm{ZnO}$ methanol synthesis catalysts - morphology effect or active site model? Applied Catalysis A: General, 208(1):163-167.

Clausen, B. S., Schiøtz, J., Gråbæk, L., Ovesen, C. V., Jacobsen, K. W., Nørskov, J. K., and Topsøe, H. (1994). Wetting/non-wetting phenomena during catalysis: Evidence from in situ on-line EXAFS studies of $\mathrm{Cu}$-based catalysts. Topics in catalysis, 1(3-4):367-376.

340 Fiedler, E., Grossmann, G., Kersebohm, D. B., Weiss, G., and Witte, C. (2000). Methanol. Wiley-VCH Verlag GmbH \& Co. KGaA.

Fujitani, T. and Nakamura, J. (1998). The effect of $\mathrm{ZnO}$ in methanol synthesis catalysts on $\mathrm{Cu}$ dispersion and the specific activity. Catalysis letters, 56(23):119-124. (1986). Chemical Equilibria in Methanol Synthesis. Chemical Engineering Science, 41(11):2883-2890.

Graaf, G. H., Stamhuis, E. J., and Beenackers, A. A. C. M. (1988). Kinetics of low-pressure methanol synthesis. Chemical Engineering Science, 43(12):3185-3195.

Grunwaldt, J.-D., Molenbroek, A. M., Topsøe, N.-Y., Topsøe, H., and Clausen, B. S. (2000). In situ investigations of structural changes in $\mathrm{Cu} / \mathrm{ZnO}$ catalysts. Journal of Catalysis, 194(2):452-460.

Holmstroem, K. (1997). TOMLAB - An Environment for Solving Optimization Problems in MATLAB. In PROCEEDINGS FOR THE NORDIC MATLAB CONFERENCE ' 97 , pages 27-28.

Kalz, K. F., Kraehnert, R., Dvoyashkin, M., Dittmeyer, R., Gläser, R., Krewer, U., Reuter, K., and Grunwaldt, J.-D. (2017). Future Challenges in Heterogeneous Catalysis: Understanding Catalysts under Dynamic Reaction Conditions. ChemCatChem, 9(1):17-29. 
Larsen, H. H. and Sønderberg Petersen, L. (2013). DTU international energy report 2013: Energy storage options for future sustainable energy systems. Technical University of Denmark.

Martín, M. (2016). Methodology for solar and wind energy chemical storage facilities design under uncertainty: Methanol production from co 2 and hydrogen. Computers \& Chemical Engineering, 92:43-54.

MATLAB (2014). version 8.4.0.150421 (R2014b). The MathWorks Inc., Natick, Massachusetts.

Muhler, M., Törnqvist, E., Nielsen, L. P., Clausen, B. S., and Topsøe, H. (1994). On the role of adsorbed atomic oxygen and CO2 in copper based methanol synthesis catalysts. Catalysis letters, 25(1-2):1-10.

Nakamura, J., Choi, Y., and Fujitani, T. (2003). On the issue of the active site and the role of $\mathrm{ZnO}$ in $\mathrm{Cu} / \mathrm{ZnO}$ methanol synthesis catalysts. Topics in catalysis, 22(3-4):277-285.

Olah, G. A. (2004). After Oil and Gas: Methanol Economy. Catalysis Letters, $93(1): 1-2$.

Olah, G. A. (2005). Beyond Oil and Gas: The Methanol Economy. Angewandte Chemie International Edition, 44(18):2636-2639.

Ovesen, C. V., Clausen, B. S., Schiøtz, J., Stoltze, P., Topsøe, H., and Nørskov, J. K. (1997). Kinetic implications of dynamical changes in catalyst morphology during methanol synthesis over $\mathrm{Cu} / \mathrm{ZnO}$ catalysts. Journal of Catalysis, 168(2):133-142.

Park, N., Park, M.-J., Ha, K.-S., Lee, Y.-J., and Jun, K.-W. (2014a). Modeling and analysis of a methanol synthesis process using a mixed reforming reactor: perspective on methanol production and $\mathrm{CO}_{2}$ utilization. Fuel, 129:163-172. 
Park, N., Park, M.-J., Lee, Y.-J., Ha, K.-S., and Jun, K.-W. (2014b). Kinetic modeling of methanol synthesis over commercial catalysts based on threesite adsorption. Fuel Processing Technology, 125:139-147.

Schwaab, M. and Pinto, J. C. (2007). Optimum reference temperature for reparameterization of the Arrhenius equation. Part 1: Problems involving one kinetic constant. Chemical Engineering Science, 62(10):2750-2764.

Tawarmalani, M. and Sahinidis, N. V. (2005). A polyhedral branch-and-cut approach to global optimization. Mathematical Programming, 103:225-249.

Vesborg, P. C. K., Chorkendorff, I., Knudsen, I., Balmes, O., Nerlov, J., Molen410 O. (2012). Detailed kinetic modeling of methanol synthesis over a ternary copper catalyst. Chemical engineering journal, 203:480-491.

Raeuchle, K., Plass, L., Wernicke, H.-J., and Bertau, M. (2016). Methanol for Renewable Energy Storage and Utilization. Energy Technology, 4(1):193-

Raue, A., Becker, V., Klingmüller, U., and Timmer, J. (2010). Identifiability and observability analysis for experimental design in nonlinear dynamical models. Chaos: An Interdisciplinary Journal of Nonlinear Science, 20(4):045105.

Schwaab, M., Lemos, L. P., and Pinto, J. C. (2008). Optimum reference temperature for reparameterization of the Arrhenius equation. Part 2: Problems involving multiple reparameterizations. Chemical Engineering Science, 63(11):2895-2906.

broek, A. M., Clausen, B. S., and Helveg, S. (2009). Transient behavior of $\mathrm{Cu} / \mathrm{ZnO}$-based methanol synthesis catalysts. Journal of Catalysis, 262(1):65-72. 
Vollbrecht, B. (2007). Zur Kinetik der Methanolsynthese an einem technischen $\mathrm{Cu} / \mathrm{ZnO} / \mathrm{Al}_{2} \mathrm{O}_{3}$-Katalysator. $\mathrm{PhD}$ thesis, Otto-von-Guericke-Universität Magdeburg.

Wilmer, H. and Hinrichsen, O. (2002). Dynamical changes in $\mathrm{Cu} / \mathrm{ZnO} / \mathrm{Al} 2 \mathrm{O} 3$ catalysts. Catalysis letters, 82(1-2):117-122.

Wulff, G. (1901). Zur Frage der Geschwindigkeit des Wachstums unter Auflösung der Kristallflächen. Zeitschrift für Krystallographie und Mineralogie, 34:449-530.

Xu, J. and Froment, G. F. (1989). Methane steam reforming, methanation and water-gas shift: I. intrinsic kinetics. AIChE Journal, 35(1):88-96. 